\title{
Estudos de otimização do desmonte de rocha para abertura de poços rasos (shallow well)
}

\author{
Marcilho José Dias Vieira ${ }^{1 *}$ (1) \\ Márcio Luiz de Siqueira Campos Barros ${ }^{2}$ \\ Júlio César de Souza ${ }^{2}$ \\ Robson Ribeiro Lima ${ }^{2}$
}

\begin{abstract}
Resumo
O Trabalho tem como proposta a aplicabilidade de métodos que são semelhantes à técnica de pilão para abertura de tuneis. Porém, voltado para o desmonte de rocha para abertura de "sallow well" (poços rasos) com vistas à implantação de postes de concreto para sustentação de redes elétricas na região nordeste do estado da Bahia. Os trabalhos de campo foram realizados nos municípios de atuação da Energia Brasil Projetos e Construções Elétricas LTDA, empresa na qual cedeu o espaço para a realização do projeto. Foram sugeridas cinco configuração distintas de perfuração e aplicadas em campo, sem descuidar dos parâmetros que regem o desmonte de rocha, tais como: afastamento, espaçamento, comprimento do furo, tampão, inclinação e razão de carga. Objetivando o melhor aproveitamento na distribuição da carga no shallow well e fazendo com que o material tenha uma fragmentação satisfatória. Todos os trabalhos de campo foram executados usando cinco combinações de configurações diferentes de furos, classificando-os em: métodos I, II, II, IV, e V. Todos os cinco métodos foram catalogados por meio de registros fotográficos. A exequibilidade dos trabalhos práticos teve como fator primordial a segurança. Portanto, foi adotado um sistema de abafamento para evitar o ultra lançamento de fragmentos rochosos durante a detonação do shallow well, reduzindo os danos a terceiros.
\end{abstract}

Palavras-chave: Desmonte; Explosivo; Perfuração; Cava.

\section{Studies of optimization of rock disassembly for the opening of shallow well}

\begin{abstract}
This work dissertation proposes the applicability of methods that are similar to the technique of burn cut area to open underground tunnels, however, is facing the opening to "shallow well" (shallow wells) for placement of concrete poles for support of electrical networks in the state of Bahia. The field work was conducted in the region where is action the Energia Brasil Projetos e Construções Elétricas Ltda, a company in which donated the location for the realization of the project. Have been suggested five distinct configurations of drilling and applied in the field, without neglecting the parameters tha rules the rock blasting, such as burden, spacing, hole length, stemming, drill angle and power factor, aiming to better use in load distribution in short wise, causing the material to be broken efficiently. All work in the field were performed using five different combinations of configurations of holes, classifving them into: methods 1, 2, 3, 4, 5. All five methods were categorized by photographic record. The feasibility of practical work had as its factor primary the safety. Therefore, will be studied methods to avoiding flyrocks fragments during blasting of pits with muffling during rock blasting in the short wise, reducing damage to third parties.
\end{abstract}

Keywords: Rock Blasting; Explosive; Drilling; Pit.

${ }^{1}$ Engenharia de Minas, Campina Grande, PB, Brasil.

${ }^{2}$ Departamento de Engenharia de Minas, Universidade Federal de Pernambuco, UFPE, Recife, PE, Brasil.

*Autor correspondente: marcilho.engminas@gmail.com

2176-1523 (C) 2022. Vieira et al. Publicado pela ABM. Este é um artigo publicado em acesso aberto (Open Access) sob a licença Creative Commons Attribution, que permite uso, distribuição e reprodução em qualquer meio, sem restrições desde que o trabalho original seja Commons Attribution,
corretamente citado. 


\section{Introdução}

Segundo Herrmann a colocação de postes e torres em terreno rochoso tem sido motivo de grande preocupação para o engenheiro que necessita resolver este problema. A preocupação não é motivada tanto pela dificuldade de executar, mas principalmente pela falta de um método simples e racional para escavação de rocha, que resulte numa cava mínima, por um custo menor [1]. O objetivo geral do trabalho é avaliar de forma comparativa cinco diferentes métodos, na qual possamos melhorar o desmonte de rochas em "shallow well" para implantação de poste para a distribuição da rede elétrica. Dentro deste contexto busca-se o cumprimento dos seguintes objetivos específicos: Melhorar a fragmentação do material desmontado; diminuir a carga específica de explosivos utilizados no desmonte do maciço rochoso; melhorar a segurança no desmonte. O projeto tem como proposta a obtenção de melhoria no desempenho do desmonte, aumento da eficiência/produtividade, consequentemente redução dos custos para melhorar a rentabilidade e competitividade da empresa. Contudo, essa otimização só será possível com a análises de alguns parâmetros importantes, no que diz respeito ao desmonte de rocha em shallow well, tais como: carga explosiva, malha de perfuração, fragmentação e perfuração. De acordo com Silva [2], os explosivos podem ser separados em duas categorias: altos explosivos e baixos explosivos. Os baixos explosivos são classificados como pirotécnicos e propelentes. Os explosivos pirotécnicos, quando queimados, produzem calor, luz, fumaça, gás e som. Já propelentes são materiais que queimam e produzem gases para a realização de trabalho mecânico, como no lançamento de um projétil e na propulsão de foguetes. Altos explosivos ou iniciadores são produtos químicos que oferecem uma maior facilidade de decomposição quando excitados por agentes externos. Podem ser subdivididos em primários, secundários e terciários. Segundo Geraldi [3], o plano de fogo é o projeto executivo para o desmonte (escavação) de rocha com uso sistemático de explosivos, onde serão definidos e apresentados preliminarmente: o plano de perfuração; a qualificação e quantificação dos explosivos e os esquemas de ligação e iniciação entre os furos que serão detonados. Para o desmonte em zona urbana Nieble [4] faz recomendações a qual os cuidados em desmontes em zona urbana devem visar à segurança das estruturas e principalmente prevenir o desconforto do meio. Ainda Nieble, diz que a partir das leis de propagação de vibrações, pode-se calcular a carga por espera e dimensionar o plano de fogo e a cobertura a ser utilizada, respeitando os critérios de segurança estrutural e do meio ambiente. Os desmontes de rocha com utilização de explosivos originam efeitos secundários de vários tipos, que podem ter grandes influências sobre $o$ ambiente vizinho, constituindo muitas vezes fatores limitantes nas operações de exploração de recursos minerais, ou de dificuldades na execução de obras civis [5]. Para o desmonte econômico, é necessário que a rocha a ser desmontada tenha face livre. Em algumas aplicações de desmontes essas faces livres inexistem. É o caso do desenvolvimento de túneis, poços (shafts), e outras aberturas subterrâneas, onde se torna necessário criar faces livres artificialmente. Isto é feito preliminarmente no desmonte principal, através da perfuração e detonação de uma abertura na face da perfuração. Essa abertura é denominada "pilão" (cut) [6]. O desmonte de rocha para abertura de shallow well (poço raso) irá se comportar como um pilão no desmonte subterrâneo, pois o mesmo encontra-se com toda área do seu entorno engastada por rochas, sem face livre natural. Portanto, será necessário forçar a criação de uma face livre para que as ondas de choques geradas na detonação possam agir conforme as leis do mecanismo de fragmentação da rocha.

\section{Materiais e métodos}

Foram utilizados neste trabalho os equipamentos de perfuração tais como: perfuratriz manual acionado por compressor de ar, explosivos da fabricante Orica usados para a detonação da poço raso. A fase de campo foi iniciada com o acompanhamento das atividades de desmonte de rocha realizada pela empresa, a qual cedeu a área para o desenvolvimento deste estudo. Após acompanhar todo o processo de execução do desmonte, registrado por meio de fotos, as etapas de perfuração, carregamento do furo e detonação, foram analisadas in loco o resultado. Concluída essa primeira etapa, iniciou-se a execução dos trabalhos deste projeto que consta de cinco configurações distintas de malha de perfuração, que foram carregadas e detonadas em seguida. Foram realizados três ensaios de cada configuração, para que assim possa ter uma maior confiabilidade dos resultados obtidos em campo. Os materiais explosivos utilizados no desmonte, são: Amex 3500, tipo granulado, disponível em sacos de 25 (vinte e cinco) quilogramas, fabricante Orica; Emulsão encartuchada "Senatel", dimensão 1x8, disponível em caixas de 25 (vinte e cinco) quilogramas; cordel detonante flexível Manticord NP05 enroladas em bobinas com 750 (setecentos e cinquenta) metros, fabricante Orica; Espoleta Mantopim, vem em caixas com 250 (duzentos e cinquenta) peças, fabricante Orica. Todos os produtos são requeridos por meio de uma autorização especial emitida pelo Serviço de Fiscalização de Produtos Controlados - SFPC do Exército Brasileiro, que por sua vez, só é emitido para a empresa que possui o Certificado de Registro - CR, documento também emitido pelo SFPC. Todo material deve sair do paiol do fornecedor rastreado e transportado em carro adaptado conforme especificações da norma R-105. Este trabalho foi desenvolvido em duas etapas que consistiram na aplicação em campo dos métodos propostos neste projeto, onde foram incorporados a aplicação do experimento as situações reais enfrentadas diariamente na atividade de desmonte de rocha para colocação de poste. A etapa seguinte foi o tratamento em laboratório dos registros fotográficos das aplicações dos métodos realizado no campo, e posteriormente a análise dos resultados.

A metodologia consiste na aplicação de cinco configurações de furos distintas, cada configuração foi designada por uma letra do alfabeto que compreende entre A e E, com propósito de compreensão deste trabalho, como mostra a Figura 1. 


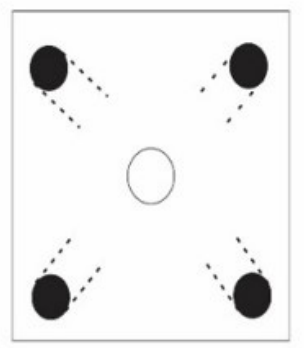

A

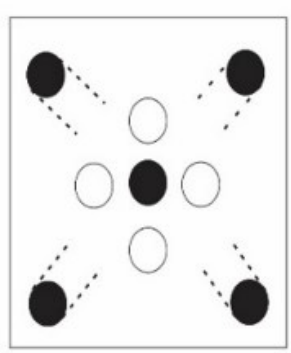

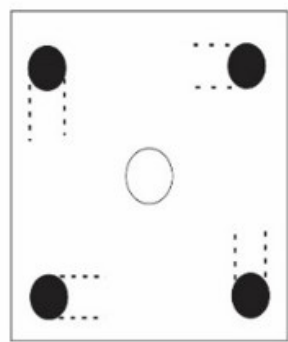

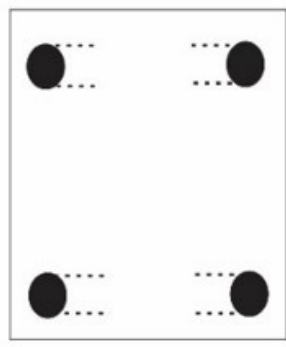

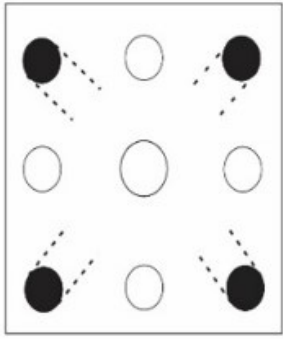

C

Legenda:

Furo carregado

Furo vazio

Inclinação

Figura 1. Diagrama dos métodos.

A configuração "A" consiste de cinco furos enumerados no sentido horario com inclinação dos furos convergente para o centro do poço, onde quatro dos cinco furos são carregados, enquanto o do centro fica vazio, servindo como uma face livre, a profundidade dos furos é a mesma do próprio poço, como mostra a Figura 2, e entre os furos carregados foram conectados retardos de 17 (dezessete) milissegundos, sendo detonados dois furos de cada vez.

O método de configuração B consiste também em cinco furos, porém com direção de inclinação diferente da configuração anterior. Quatro furos nas extremidades do poço raso e um furo na vertical sem carregar no centro. As inclinações dos quatro furos são de $5^{\circ}$ com direção ao furo vizinho, Figura 3.

A configuração $\mathrm{C}$ consiste na perfuração de nove furos enumerados no sentido horário, porém somente cinco dos nove furos são carregados com explosivos. A distribuição dos furos é composta de quatro na extremidade do poço raso com um furo no centro e mais quatro furos vazios intercalados com os das extremidades. Os quatro furos que estão localizados na extremidade do poço raso são inclinados com $5^{\circ}$ convergentes na direção do centro. Os demais são perfurados verticalmente, como mostra a Figura 4.

Por sua vez, a configuração D é formada também com nove furos enumerados seguencialmente no sentido horário, sendo quatro nas extremidades do poço, um no centro e outros quatro perfurados ao redor do furo central. Os furos das extremidades são inclinados também com $5^{\circ}$ e carregados como o furo central. Os quatro furos ao redor do central são vazios formando uma zona de faces livres, Figura 5.

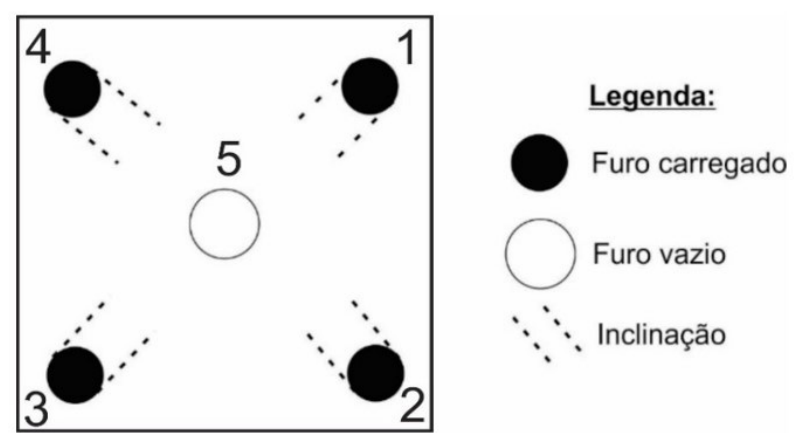

Figura 2. Configuração A contém furos de $38 \mathrm{~mm}$ de diâmetro e profundidade de $1,10 \mathrm{~m}$. Seguência de detonação: 1 e 2 foram detonados instantâneamente e em seguida 3 e 4.

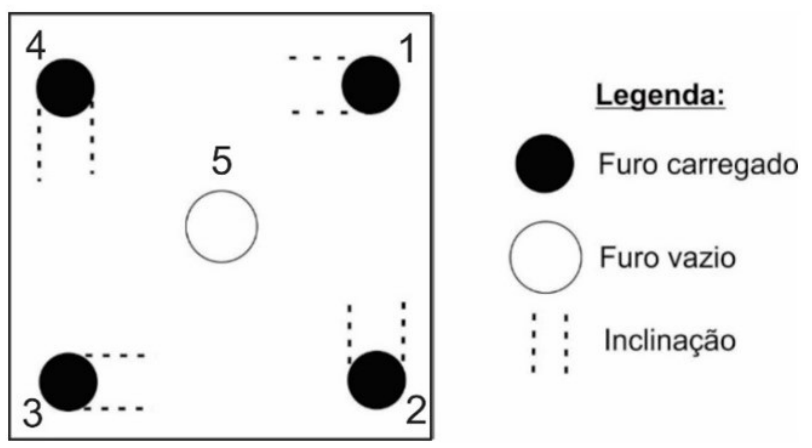

Figura 3. Configuração B.contém furos de $38 \mathrm{~mm}$ de diâmetro e profundidade de 1,20 m.: Os furos:1, 2, 3 e 4 foram detonados instantâneamente. 


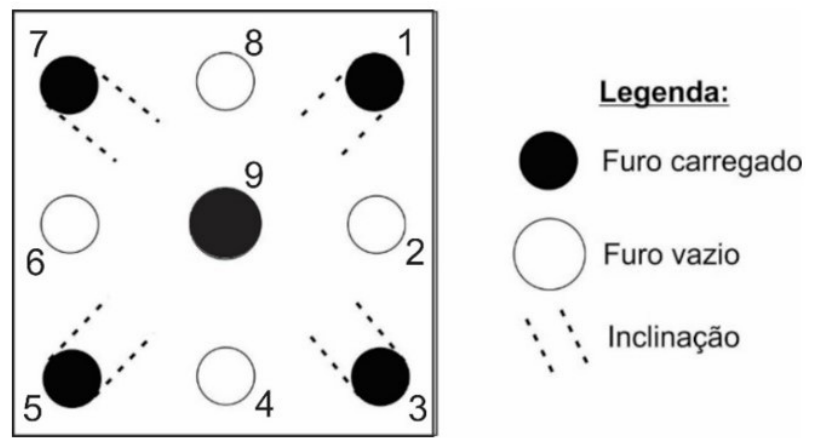

Figura 4. Configuração C. contém furos de $38 \mathrm{~mm}$ de diâmetro e profundidade de 1,17 m.: Os furos:1, 3, 5, 7 e 9 foram detonados instantaneamente.
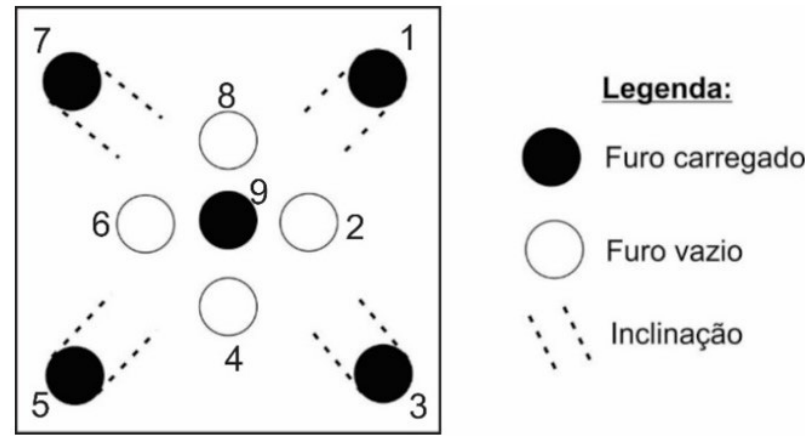

Figura 5. Configuração D.contém furos de $38 \mathrm{~mm}$ de diâmetro e profundidade de 0,90 m.: Os furos:1, 3, 5, 7 e 9 foram detonados instantâneamente.

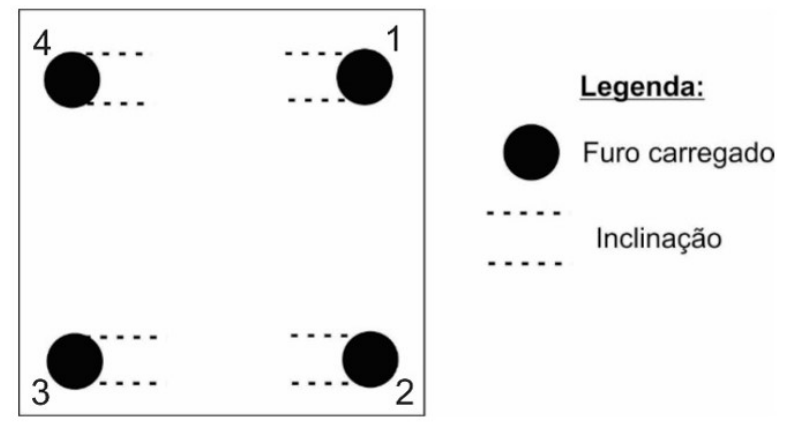

Figura 6. Configuração E contém furos de $38 \mathrm{~mm}$ de diâmetro e profundidade de 1,50 m.: Os furos:1, 2, 3, e 4 foram detonados instantâneamente.

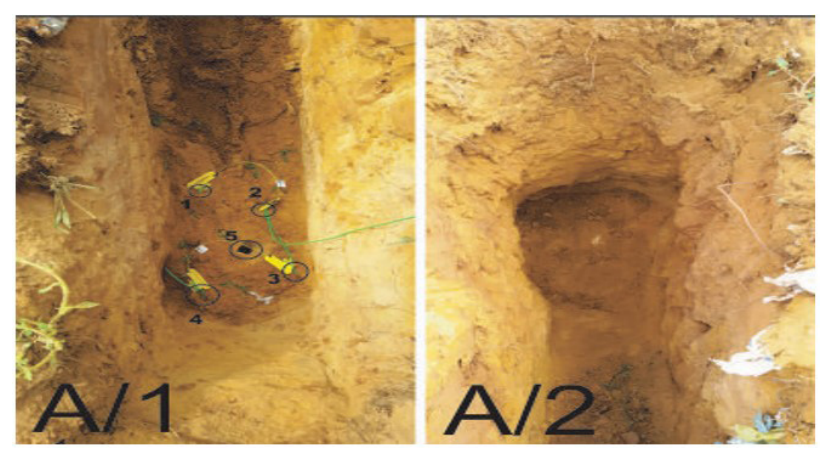

Figura 7. A/1 - configuração A carregada; A/2 resultado da detonação.
E por último a configuração E consiste de quatro furos enumerados seguencialmente no sentido horário, feitos nas extremidades do poço, e inclinados em $5^{\circ}$ na direção do furo da frente. Neste método de configuração não há furo de alívio, ou seja, todos são carregados e por esta razão não há nenhuma face livre, Figura 6.

$\mathrm{O}$ uso de explosivo em obras civis é um assunto complexo que envolve um fator de extrema relevância para execução do projeto: onde serão executados os desmontes, se área urbana ou região desabitada. Em áreas urbanas o desmonte deverá tomar alguns cuidados, tais como: a projeção de blocos rochosos; a geração de vibração pelo terreno, fator que pode causar danos materiais nas estruturas próximas ao desmonte; e até perdas humanas, por se tratar do uso de material de alta periculosidade.

\section{Resultados e discussões}

\subsection{Método I}

Foram realizadas perfurações com cinco furos de 1,10 (um e dez) metros de comprimento cada, sendo o furo localizado no centro do shallow well é vazio e sem inclinação. Os quatro furos localizados nas extremidades foram perfurados com uma leve inclinação de $5^{\circ}$ direcionado para o furo central (configuração A), Figura 7. Os furos 1 (um), 2 (dois), 3 (três) e 4 (quatro) foram projetados para estarem dispostos de maneira a formar um quadrado com os lados de quarenta centímetros. Porém, durante a execução dos furos no shallow well, os furos 2 (dois) e 3 (três) ficaram a uma distância diferente ao projetado, devido a impossibilidade de executarem os furos de acordo com o planejado. A utilização da configuração A apresentou resultados satisfatórios no que diz respeito à detonação de shallow well para colocação de poste, pois o arranjo dos furos mostrou que a área de influência sobre a qual a energia age para fragmentar o material rochoso e o emprego do furo central vazio, fazendo com que abrisse uma suposta face livre para gerar as ondas de reflexão (onda de contração) que origina a fragmentação da rocha. Esse método maximizou essa energia fazendo com que o material fosse fragmentado de maneira tal que se chegasse ao objetivo final que é a profundidade ideal para o engaste do poste, sem ocorrer o desmonte secundário (repasse), comparado ao método padrão, Figura 7A/2.

\subsection{Método II}

Neste método foi executada a configuração B que consiste de cinco furos, nos quais quatro são carregados com explosivos. Os furos tiveram comprimento de 1,20 (um e vinte) metros, sendo que quatro furos com uma suave inclinação de $5^{\circ}$ convergindo para o furo adjacente no sentido anti-horário. $\mathrm{O}$ furo 1 (um) inclina em direção 
ao furo 4 (quatro), o furo 4 (quatro) inclina no sentido do furo 3 (três), por sua vez, o furo 3 (três) converge sua inclinação para o furo 2 (dois), conforme Figura 3. Os furos um, dois, três e quatro foram carregados com exceção do furo cinco. Foi utilizado explosivo granulado de densidade $0,81 \mathrm{~g} / \mathrm{m}^{3}$ e $1 / 2$ encartuchado em cada furo carregado. $\mathrm{O}$ cordel empregado na detonação foi NP-05 da fabricante Orica, Figura 8B/1. Para iniciação do fogo foi utilizado o conjunto estopim/espoleta $\mathrm{n}^{\mathrm{o}} 8$ de comprimento 1 (um) metro também da fabricante Orica. Foram detonados todos os furos carregados no mesmo momento, sem existir uma sequência de detonação dos furos. O resultado observado do método II após a detonação do shallow well (poço raso) também se mostrou satisfatório, pois fragmentou o material de tal modo que atingiu a profundidade ideal de engaste do poste, que neste caso, foi de 1,70 (um e setenta) metros, Figura 8B/2. A remoção do material fragmentado não foi realizada no mesmo dia, devido ao horário está no final de expediente e ausência de pessoal destinado para tal serviço. Porém, no dia seguinte foi retirado todo material do poço raso (shallow well) e verificou que o mesmo não necessitou de um segundo fogo.

\subsection{Método III}

Neste método foi utilizado a configuração E composto por quatro furos sendo que a inclinação do furo 1 (um) converge para o furo 2 (dois), igualmente o furo 2 (dois) inclina em direção ao furo 1 (um). Consequentemente, o furo 3 (três) inclina no sentido do furo 4 (quatro), que por sua vez, inclina-se para o furo 3 (três), Figura 9E/1.

O comprimento dos furos é de 1,50 (um e cinquenta) metros e seu diâmetro de 38 (trinta e oito) milímetros. Todos os furos foram carregados com explosivo granulado, $1 / 2$ encartuchado em cada furo carregado, cordel NP-05 e conjunto estopim/espoleta $\mathrm{n}^{\circ} 8$ de comprimento de 1 (um) metro. A sequência de detonação iniciou nos furos 1 (um) e 2 (dois), em seguida foram detonados os furoa 3 (três) e 4 (quatro) ao mesmo tempo. O retardo utilizado entre os furos 1 (um), 4 (quatro), 2 (dois) e 3 (três), foi de 17 (dezessete) milissegundos. O método em questão mostrou-se eficaz, atingindo o resultado esperado. $\mathrm{O}$ emprego dos retardos na detonação dos furos melhorou significativamente o desmonte do poço raso (shallow well) alcançando a profundidade adequada para a fixação do poste, sem que haja a necessidade de uma segunda detonação, Figura 9E/2.

\subsection{Método IV}

Este método é composto pela configuração D, na qual foram perfurados nove furos com diâmetros de 38 (trinta e oito) milímetros e profundidade de 90 (noventa) centímetros, tendo em vista que o poste implantado é 9 (nove) metros de comprimento, portanto, seu engaste conforme norma do manual de construção elétrica é de 1,50 (um e cinquenta) metros de comprimento. Entretanto, o objetivo desse método

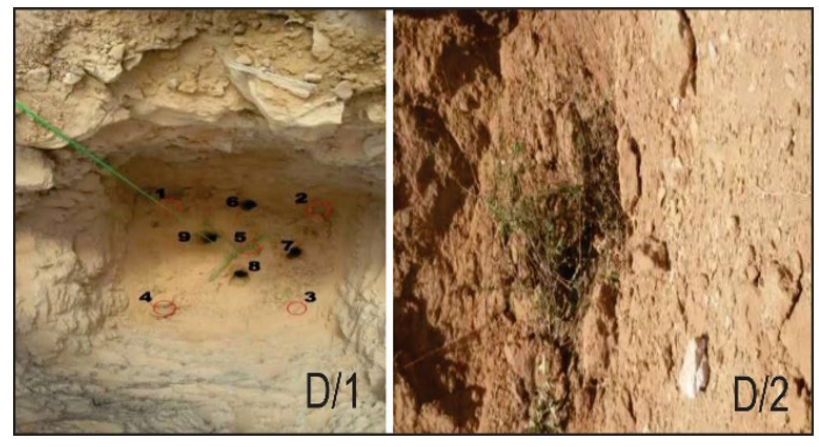

Figura 8. B/1 - configuração B carregada; B/2 - resultado da detonação.

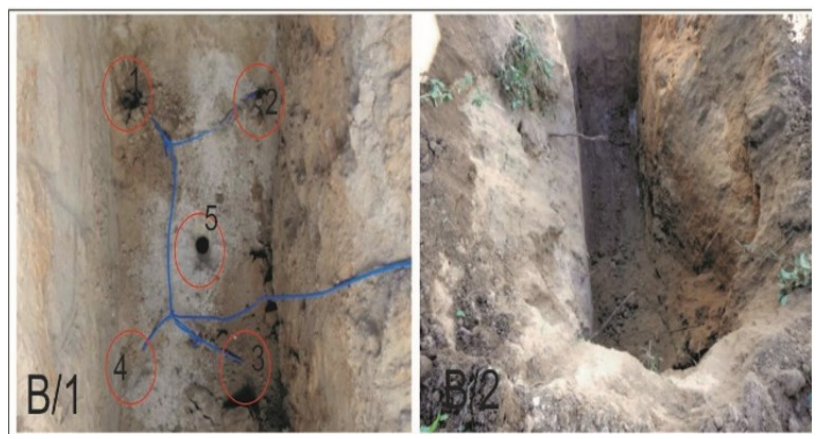

Figura 9. E/1 - configuração E carregada; E/2 - resultado da detonação.

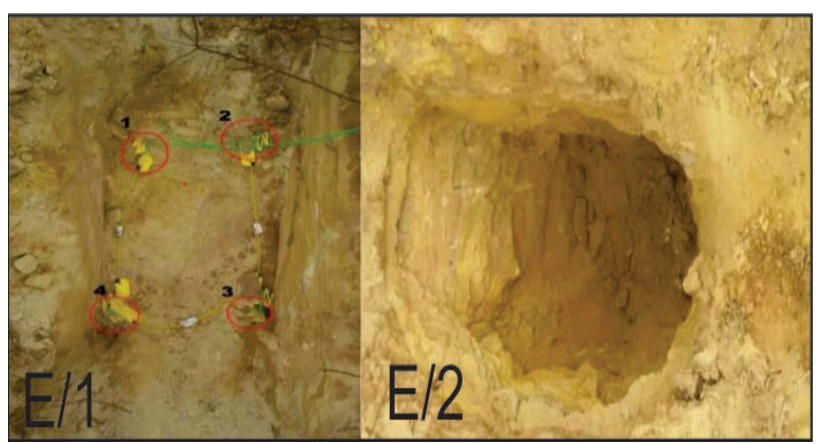

Figura 10. D/1- configuração D carregada; D/2 - resultado da detonação.

é mostrar o desempenho na abertura do shallow well, alcançando de forma eficiente à profundidade de engaste do poste, que neste caso, é de 1,50 (um e cinquenta) metros. A perfuração consiste em nove furos, entre os quais cinco foram perfurados com uma inclinação de $5^{\circ} \mathrm{e}$ os demais sem inclinação. Os furos 1 (um), 2 (dois), 3 (três), 4 (quatro) e 5 (cinco) foram carregados com explosivo na forma granular, tendo em todos os furos carregado $1 / 2$ cartucho de emulsão. Sendo iniciado com cordel detonante NP-05 e conjunto estopim/espoleta $\mathrm{n}^{\circ} 8$ de 1 (um) metro de comprimento. Os demais furos não foram carregados, servindo como face livre para os furos carregados, Figura 10D/1. Este método, como os demais, obteve resultado esperado, pois alcançou a profundidade de engaste do poste, que é de 1,50 (um e cinquenta) metros. 


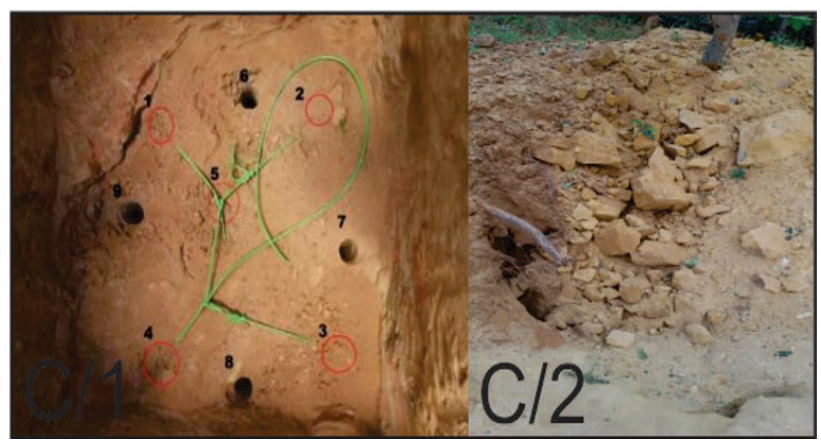

Figura 11. C/1- configuração C carregada; $\mathrm{C} / 2$ - resultado da detonação.

O furo só foi limpo no dia seguinte da detonação, devido à ausência de equipe responsável pela remoção do material detonado dentro da cava. Mas após sua limpeza foi comprovado o resultado esperado pelo método, Figura 10D/2.

\subsection{Método V}

A configuração $\mathrm{C}$ foi usada neste método na qual foram perfurados nove furos com diâmetro de 38 (trinta e oito) milímetro e 1,17 (um e dezessete) metros de profundidade. $\mathrm{O}$ arranjo dos furos no shallow well está representado na Figura 4. Dentre os nove furos perfurados, cinco foram carregados com explosivo granulado de densidade $0,81 \mathrm{~g} / \mathrm{m}^{3}$. Os furos 1 (um), 2 (dois), 3 (três), 4 (quatro) e 5 (cinco) foram interligados com cordel detonante NP-05 da fabricante Orica, Figura 11C/1. A detonação do shallow well foi iniciada com o conjunto estopim/espoleta $\mathrm{n}^{\circ} 8$, tendo como nomenclatura "mantopim". O resultado observado após a detonação, assim como os métodos anteriores, mostrou-se resultado satisfatório, pois, o material consolidado foi fraturado ao longo de todo o comprimento do furo alcançando a profundidade desejada para o engaste do poste, sem que haja a necessidade de uma segunda detonação, objetivo desse trabalho, Figura 11C/2.

\section{Conclusão}

A detonação para colocação de postes de sustentação de rede elétrica é uma atividade de desmonte de rocha de pequena escala comparado ao desmonte de bancada, onde se trabalha com pequenas quantidades de explosivos e manuseio no seu carregamento de forma rápida. A mão de obra responsável pala execução de Shallow well (poço raso) para a colocação de poste na rede elétrica, apesar da pouca capacitação na execução do poço raso para os métodos propostos, assimilou rapidamente a nova metodologia. A utilização de outras formas de configurações de furos, comparada ao praticado pela empresa para o desmonte de Shallow well (poço raso), mostrou resultados satisfatórios. Uma vez que, nos métodos testados em campo puderam ser observados o bom desempenho e baixo custo de operação. Os métodos propostos por esse trabalho trouxeram alternativas de diferentes formas de se perfurar e detonar a rocha contida no poço raso, sem que haja a necessidade de fazer uma nova detonação, economizando assim, material explosivo e mão de obra. Das metodologias propostas, a segunda, além de uma execução mais fácil, pela mão de obra local, apresentou um ótimo resultado na fragmentação e o menor custo de produção de todas as metodologias propostas. Entretanto, a quarta metodologia apesar de mostrar um ótimo resultado na fragmentação das rochas, apresentou um maior grau de dificuldade na sua execução por parte da mão de obra local.

\section{Referências}

1 Herrmann C. Manual de perfuração de rocha. São Paulo: Polígono; 1972.

2 Silva CV. Desmonte de rocha. São Paulo: Oficina de Textos; 2019.

3 Geraldi JLPO. ABC das escavações de rocha. Rio de Janeiro: Interciência; 2011.

4 Nieble CM. Desmontes cuidadosos com explosivos: aspectos de engenharia e ambientais. São Paulo: Oficina de Textos; 2017.

5 Vieira MJD. Estudos de otimização do desmonte de rocha para abertura de poços rasos (shallow well) [dissertação]. Recife: Universidade Federal de Permanbuco; 2014.

6. Silva VC. Curso de desmonte de rocha por explosivos. Natal: Crea; 2015.

Recebido em: 17 Nov. 2020

Aceito em: 19 Mar. 2021 